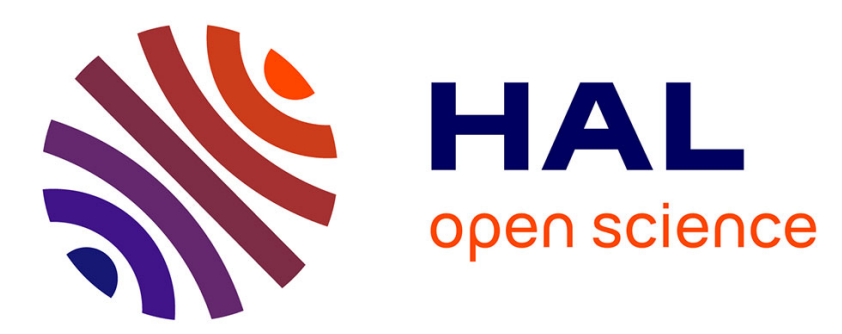

\title{
Estimation of nitrogen-to-carbon ratios of organics and carbon materials at the submicrometer scale
}

\author{
Julien Alleon, Sylvain Bernard, Laurent Remusat, François Robert
}

\section{To cite this version:}

Julien Alleon, Sylvain Bernard, Laurent Remusat, François Robert. Estimation of nitrogen-to-carbon ratios of organics and carbon materials at the submicrometer scale. Carbon, 2014, 84, pp.290-298. 10.1016/j.carbon.2014.11.044 . hal-01090504

\section{HAL Id: hal-01090504 https://hal.science/hal-01090504}

Submitted on 3 Dec 2014

HAL is a multi-disciplinary open access archive for the deposit and dissemination of scientific research documents, whether they are published or not. The documents may come from teaching and research institutions in France or abroad, or from public or private research centers.
L'archive ouverte pluridisciplinaire HAL, est destinée au dépôt et à la diffusion de documents scientifiques de niveau recherche, publiés ou non, émanant des établissements d'enseignement et de recherche français ou étrangers, des laboratoires publics ou privés. 


\section{Estimation of nitrogen-to-carbon ratios of organics and carbon materials at the submicrometer scale}

Julien Alleon, Sylvain Bernard", Laurent Remusat, François Robert

Institut de Minéralogie, de Physique des Matériaux et de Cosmochimie (IMPMC), Sorbonne Universités - CNRS UMR 7590, Muséum National d'Histoire Naturelle, UPMC Univ Paris 06, IRD UMR 206, 61 rue Buffon, 75005 Paris, France.

* corresponding author : sbernard@mnhn.fr

Abstract:

Precisely estimating nitrogen-to-carbon (N/C) ratio of carbonaceous materials at the submicrometer scale is a challenge in both natural and material sciences. Following recent attempts reported in the literature, the present paper discusses two methods of quantification of the N/C ratio or organics and carbon materials at the submicrometer scale using nanoscale secondary ion mass spectrometry (NanoSIMS) and X-ray absorption spectroscopy (XAS). The present data highlight the need to use at least two standards to build a calibration line in order to precisely and accurately ( \pm 0.009 - $95 \%$ confidence level) estimate N/C values of unknown carbon samples using NanoSIMS. As shown here using a set of reference compounds, STXM-based XAS allows directly estimating N/C ratios of organics without using any standard with errors as low as 0.007 .

1 Introduction:

Understanding the impact of nitrogen incorporation on carbon material properties at the submicrometer scale is important for many scientific domains ranging from pedology and the study of organics in soils (e.g., [1,2]) to

\footnotetext{
* Corresponding author. Tel: +33 (0)1 407935 32. E-mail: sbernard@mnhn.fr
} 
micropaleontology and the search for the oldest traces of life in rocks (e.g., $[3,4])$, through material science and the study of properties of $\mathrm{N}$-doped carbon materials (e.g., [5-7]).

Processes occurring in soils, such as sequestration of organics, may play a crucial role in reducing the atmospheric $\mathrm{CO}_{2}$ enrichment and improving biomass/agronomic productivity for instance ([8-10]). These processes are intimately controlled by organic carbon and nitrogen fluxes [11,12]. As soils may appear very heterogeneous at all scales of observation [11,12], better constraining such processes requires precise estimations of the N/C ratios of organics to be done at the submicrometer sale.

Precisely estimating the concentrations of nitrogen at the submicrometer scale may also help identifying organic remains of life in ancient rocks. For instance, the involvement of nitrogen, together with phosphorous and sulphur, in organic microstructures found in Gyr-old cherts has been used to discuss their biogenicity (e.g., [13-15]). In addition, precisely estimating N/C ratios of individual microfossils at the submicrometer scale might provide estimations of the degree of their preservation [16].

Nitrogen doping may profoundly affect electronic properties of carbon materials and brings along tremendous technological implications [5-7]. As the quantity of nitrogen that might be incorporated varies depending on the technique used (e.g., magnetron sputtering, laser ablation, pyrolysis or chemical vapor deposition) and as carbon nanomaterials may be strongly heterogeneous $[17,18]$, better understanding the properties of carbon materials requires precisely quantifying their $\mathrm{N} / \mathrm{C}$ ratios at the submicrometer scale.

A number of recent studies have attempted to propose new ways to precisely quantify organic N/C ratio at a small scale. For instance, Hatton et al. [1] have used Nanoscale Secondary Ion Mass Spectrometry (NanoSIMS) to provide estimations of the N/C ratio of soil organics. Yet, their methodology relies on an internal calibration requiring a large range of $\mathrm{N} / \mathrm{C}$ values to be covered by the investigated materials and is thus not universally applicable. More recently, Thomen et al. [19] have proposed a way to calibrate NanoSIMS data to estimate the N/C ratio of organics. Yet, due to large topographical effects, their calibration lacks the precision required to obtain meaningful data in the small 
range of N/C values typical of terrestrial environments. On the other hand, Cody et al. [20,21] and van Dommele et al. [22] have used synchrotron-based X-ray absorption spectroscopy (XAS) and X-ray photoelectron spectroscopy (XPS), respectively, to quantify the $\mathrm{N} / \mathrm{C}$ ratio of submicrometric organic particles or carbon materials. Unfortunately, although it would have accredited their methodology, these authors did not report any measurement on reference compounds.

The present contribution presents careful examinations of two methods recently reported in the literature for precise quantification of the N/C atomic ratio of organics at the submicrometer scale based on nanoscale secondary ion mass spectrometry (NanoSIMS) measurements and X-ray absorption spectroscopy (XAS) data collected using scanning transmission X-ray microscopy (STXM). From results obtained on a set of organic reference compounds, the present contribution discusses the validity, precision, advantages and limitations of these two methods.

\section{Materials \& Methods}

\subsection{Sample selection}

Six homogeneous organic compounds of various chemical structures covering a wide range of N/C values have been selected for the present study (Table 1). These compounds have been used as reference materials to estimate how precise and accurate can be the quantifications of $\mathrm{N} / \mathrm{C}$ atomic ratios using NanoSIMS and XAS. Among these reference samples, two natural type I and type III kerogens, a synthetic epoxide resin, two amino acids (L-Phenylalanine and LTryptophan) and an organic compound synthesized by plasma discharge on a $\mathrm{N}_{2}-$ $\mathrm{CO}$ gaseous mixture (e.g., Nebulotron; [23]). Bulk $\mathrm{N}$ and $\mathrm{C}$ concentrations have been measured by thermal conductivity on 1-2 mg aliquots (SGS Multilab) (Table $1)$. 


\begin{tabular}{|c|c|c|c|c|c|c|}
\hline Sample & $\begin{array}{l}\mathrm{N} / \mathrm{C} \\
\text { Bulk }\end{array}$ & $\begin{array}{l} \pm \quad 1 \sigma \\
\left(10^{-4}\right)\end{array}$ & $\begin{array}{l}\mathrm{CN}^{-} / \mathrm{C}_{2}{ }^{-} \\
\text {(mean } \\
\text { ROI) }\end{array}$ & $\begin{array}{l} \pm \quad 1 \sigma \\
\left(10^{-2}\right)\end{array}$ & $\begin{array}{l}\mathrm{N} / \mathrm{C} \\
\mathrm{XAS}\end{array}$ & $\begin{array}{l}\text { graphical } \\
\text { error }\left(10^{-2}\right)\end{array}$ \\
\hline $\begin{array}{l}\text { Kerogen } \\
\text { type III }\end{array}$ & 0.016 & 0.80 & 0.141 & 1.60 & 0.018 & 0.70 \\
\hline $\begin{array}{l}\text { Kerogen } \\
\text { type I }\end{array}$ & 0.025 & 1.25 & 0.238 & 2.50 & 0.025 & \\
\hline Resin & 0.053 & 2.65 & 0.491 & 2.20 & 0.053 & 2.00 \\
\hline $\begin{array}{l}\text { Phenylalani } \\
\text { ne }\end{array}$ & 0.111 & 5.55 & 0.961 & 7.10 & 0.111 & 1.00 \\
\hline Tryptophan & 0.182 & 9.10 & 1.576 & 2.90 & 0.182 & 1.00 \\
\hline Nebulotron & 0.746 & 37.3 & NA & NA & 0.700 & 1.00 \\
\hline
\end{tabular}

Table 1: Bulk N/C measurements (thermal conductivity - SGS Multilab), $\mathrm{CN}^{-} / \mathrm{C}_{2}^{-}$ ionic ratios measured by NanoSIMS and N/C ratios estimated by STXM-based XAS.

\subsection{Sample Preparation}

For NanoSIMS experiments, samples have been pressed at 0.5 ton onto clean indium foils, coated with $15 \mathrm{~nm}$ of gold and degassed in the NanoSIMS vacuum chamber for two days before analyses. For STXM experiments, the same compounds have been finely crushed, pipetted in ultrapure water and deposited on $50 \mathrm{~nm}$ thick silicon nitride windows.

\subsection{NanoSIMS}

The originality of the NanoSIMS design is that primary and secondary ion beams are sharing the same optical system. The primary beam hits the sample perpendicularly to its surface, which reduces the focal length and aberrations compared to regular SIMS, thus leading to a probe diameter as small as $50 \mathrm{~nm}$ [24]. Using the CAMECA NanoSIMS 50 at MNHN (Paris, France), secondary 
molecular ions ${ }^{12} \mathrm{C}^{14} \mathrm{~N}^{-}$and ${ }^{12} \mathrm{C}_{2}^{-}$are collected simultaneously. Due to their extremely high electron affinity [25,26] and higher stability, the yield of secondary $\mathrm{CN}^{-}$is very high compared to the one of $\mathrm{N}^{-}$. Furthermore, the $\mathrm{CN}^{-} / \mathrm{C}_{2}^{-}$ ratio appears as a more appropriate proxy for $\mathrm{N} / \mathrm{C}$ atomic ratio than $\mathrm{CN}^{-} / \mathrm{C}^{-}$which can be seen as a proxy of nitrogen concentration [19].

A $30 \mu \mathrm{m}$ entrance slit (ES3) and a $350 \mu \mathrm{m}$ aperture slit (AS1) have been used to reduce secondary ion energetic and angular dispersions, respectively. Before measurements, Cesium $\left(\mathrm{Cs}^{+}\right)$has been implanted during $7 \mathrm{~min}$ using a 200 pA primary current and a $300 \mu \mathrm{m}$ aperture diaphragm on $13 \times 13 \mu \mathrm{m}^{2}$ areas. Hence, a dose of about $3 \times 10^{17}{\mathrm{Cs} . \mathrm{cm}^{-2}}$ has been implanted before analysis to ensure stationary regime for secondary ions emission [19]. Analyses have then been performed on $10 \times 10 \mu \mathrm{m}^{2}$ areas (i.e., on areas smaller than the implanted ones to avoid edge artifacts) using a $0.5 \mathrm{pA}$ primary current and a $150 \mu \mathrm{m}$ aperture diaphragm, i.e., with a beam size of about $70 \mathrm{~nm}$. Seven cycles have been stacked to generate one image $\left(256 \times 256\right.$ pixels for $10 \times 10 \mu \mathrm{m}^{2}$ areas with a counting time of $1 \mathrm{~ms} / \mathrm{px}$ ); three images per sample have been collected.

Data acquired by NanoSIMS have been corrected for a $44 \mathrm{~ns}$ dead time on each electron multiplier and have been processed using Limage software (developed by L. Nittler, Carnegie Institution, Washington DC, USA). For each analyzed area (i.e., for each image), 10 regions of interest (ROI) of $0.7 \times 0.7 \mu \mathrm{m}^{2}$ have been manually defined on regions of samples with very low topographic variations (Figure 1; see section 3.2.2 for details).

Although there is no isobaric interference with ${ }^{12} \mathrm{C}^{13} \mathrm{C}^{1} \mathrm{H}^{-}$ions, ${ }^{13} \mathrm{C}_{2}^{-}$and ${ }^{12} \mathrm{C}^{14} \mathrm{~N}^{-}$ions cannot be separated on mass 26 . Yet, this isobaric interference is negligible, even for N-poor samples. For instance, during one cycle of measurement on the type III kerogen, 130000 counts per second (cps) of ${ }^{12} \mathrm{C}_{2}{ }^{-}$ and $20000 \mathrm{cps}$ of ${ }^{12} \mathrm{C}^{14} \mathrm{~N}^{-}$have been collected on masses 24 and 26 respectively. Based on natural abundances [27], less than $1 \%$ of these $20000 \mathrm{cps}$ are accounting from $13 \mathrm{C}_{2}^{-}$ions $(\approx 15 \mathrm{cps})$.

\subsection{STXM-based XAS}


STXM is a synchrotron-based transmission spectromicroscopy technique using a monochromated X-ray beam produced by synchrotron radiation. This technique allows both microscopic observations - i.e., imaging at the 15-nm scale - and spectroscopic measurements - i.e., recording X-ray absorption spectra with a spectral resolution of $0.1 \mathrm{eV}$ which provide information on element speciation at the same spatial scale. Measurements of the present contribution have been done using the 10ID-1 SM beamline [28] located at the Canadian Light Source (CLS). Beamline 10ID-1 uses soft X-rays (130-2500 eV) generated with an elliptically polarized undulator inserted in the $2.9 \mathrm{GeV}$ synchrotron storage ring (250-150 mA). The microscope chamber is evacuated to $100 \mathrm{mTorr}$ after sample insertion and back-filled with He. A $100 \mathrm{~nm}$ thick titanium filter is used to remove second order light when working at the $\mathrm{C}$ and $\mathrm{N} K$-edges. Energy calibration is accomplished using the well-resolved 3p Rydberg peak at $294.96 \mathrm{eV}$ of gaseous $\mathrm{CO}_{2}$ for the $\mathrm{C} K$-edge.

Here, X-ray absorption spectra have been obtained by collecting image stacks, i.e., by rastering selected areas of samples in the $x-y$ directions at energy increments of $0.25 \mathrm{eV}$ over the $270-450 \mathrm{eV}$ energy range using the low energy grating of the 10ID-1 SM beamline. This energy range covers the carbon (270$340 \mathrm{eV})$ and the nitrogen (390-450 eV) absorption ranges. Stack measurements have been performed with a dwell time of the order of a millisecond or less per pixel to avoid irradiation damages following the procedures for $X$-ray microscopy studies of radiation sensitive samples recommended by [29]. Importantly, with these settings, radiation damage per unit of analytical information has been shown to be typically 100-1000 times lower in STXM-based XANES spectroscopy compared to TEM-based EELS [30]. Note that a minimum of 20 pixels have to be summed to have a good signal/noise ratio with these settings. Alignment of images of stacks, selection of pixels, and extraction of XAS spectra have been done using the aXis2000 software (ver 2.1n). X-ray absorption spectra are measurements of absorbance (A) (also defined as transmissivity or optical density) which corresponds to the opposite of the natural logarithm of the ratio between the intensity of the radiation passing through the sample (I) and the intensity of the incident radiation $\left(\mathrm{I}_{0}\right)$ measured on a sample-free location on the silicon nitride window $\left(A=-\ln \left(I / I_{0}\right)\right)$. Estimations of 
$\mathrm{N} / \mathrm{C}$ ratios from X-ray absorption spectra have been done here using the $\mathrm{R}$ studio software (http://www.r-project.org/), although any programming language may be used.

\section{Estimation of $\mathrm{N} / \mathrm{C}$ atomic ratios}

\subsection{NanoSIMS estimation of N/C ratios}

The distribution of the mean measured $\mathrm{CN}^{-} / \mathrm{C}_{2}^{-}$values of all ROIs plotted against bulk N/C values for reference samples is well explained by a linear regression model $\left(\mathrm{R}^{2}>0.99\right.$; Figure 2$)$. Note that the regression line does not cross the origin. This might be due to the adsorption of $\mathrm{N}_{2}$ onto the sample surface despite high vacuum. N monoatoms coming from the beam-induced breaking of adsorbed $\mathrm{N}_{2}$ may participate to nonorganic $\mathrm{CN}^{-}$ions formation [31]. In any case, the present data highlight the need to use at least two standards to build such a calibration line in order to precisely and accurately $( \pm 0.009-95 \%$ confidence level) estimate N/C values of unknown carbon samples.

\subsection{STXM-based XAS estimation of N/C ratios}

According to the Beer-Lambert law [32], the intensity of the radiation passing through the sample (I) is related to the intensity of the incident radiation $\left(I_{0}\right)$ following the equation $\mathrm{I}=\mathrm{I}_{0} \mathrm{e}^{-\mu 1 \rho}$ with $\mu$ the mass absorption coefficient, 1 the thickness of the sample and $\rho$ its volumetric mass density. The absorption signal $\left(A=-\ln \left(I / I_{0}\right)\right)$, i.e., the absorbance or optical density, is thus the product of the thickness times the volumetric mass density times the mass absorption coefficient $(\mathrm{A}=\mu \mathrm{l} \rho)$. According to Henke et al. [33,34], for a given element, the mass absorption coefficient $(\mu)$ is directly proportional to the atomic photoabsorption cross section $\left(\sigma_{a}\right)$, which is itself directly proportional to the $f_{2}$ component (imaginary part) of the complex atomic scattering factor. (Note that the $\mathrm{f}_{2}$ components of most elements can be found online: http://henke.lbl.gov/optical_constants/). 
The optical properties of any material in the photon energy range below and above the edge regions of its constituted elements can be described by the atomic scattering factors $[33,34]$. Thus, for a given area of a sample (i.e., for a given thickness and a given volumetric mass density), an atomic ratio can be directly estimated by dividing the coefficients used to fit the sum of the $f_{2}$ components of carbon and nitrogen to the measured absorption signal below and above the edge regions. The absorption signal over the carbon and nitrogen edge regions (280-330 eV and 395-430 eV, respectively) is not fitted as this signal is dominated by peaks corresponding to electronic transitions as well as by broad spectral features corresponding to highly delocalized excited states sometimes referred to as virtual state transitions or the overlapping contribution of Feshbach resonances $[35,36]$. A typical resulting fit in the energy range covering the $\mathrm{C}$ and $\mathrm{N} K$-edges, i.e., the sum $\mathrm{K}_{\mathrm{C}} \times \mathrm{f}_{2 \text { (carbon) }}+\mathrm{K}_{\mathrm{N}} \times \mathrm{f}_{2 \text { (nitrogen), }}$ is shown on Figure 3 . The ratio $\mathrm{K}_{\mathrm{N}} / \mathrm{K}_{\mathrm{C}}$ constitutes an estimation of the $\mathrm{N} / \mathrm{C}$ ratio of the investigated carbon material.

Figure 4 shows the X-ray absorption spectra of the six organic reference compounds used for the present contribution and the respective resulting fits of

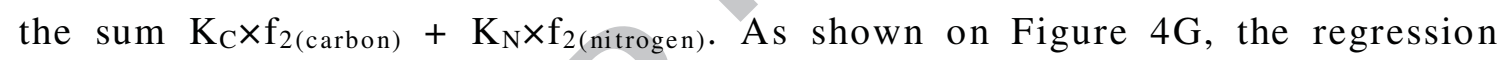
curve between the ratios $\mathrm{K}_{\mathrm{N}} / \mathrm{K}_{\mathrm{C}}$ and the $\mathrm{N} / \mathrm{C}$ bulk measurements is very close to a straight line with a slope of 1 passing through the origin. Note that the XASbased estimations of N/C ratios perfectly match the exact values measured on bulk powders for the purest organic compounds used in the present contribution (i.e., the synthetic epoxide resin and the two pure amino acids). The slight deviation of the linear regression line slope likely results from the chemical heterogeneous nature of the two kerogens and the Nebulotron samples at the submicrometer scale. Importantly, the fact that the regression line passes through the origin suggests that nitrogen adsorbed onto the sample surface does not contribute to the absorption signal.

\section{Discussion}

\subsection{NanoSIMS measurements}


4.1.1. Linear Response, Repeatability, Prediction Interval, Limits of Detection and Quantification

The prediction interval (PI) corresponds to the uncertainty on the predicted N/C value inverted from a $\mathrm{CN}^{-} / \mathrm{C}_{2}^{-}$measurement (Figure 2). It differs from the confidence interval (CI), which represents the uncertainty of the mean values, by taking into account the fluctuation of $\mathrm{CN}^{-} / \mathrm{C}_{2}^{-}$measurements around the mean value (Figure 2). The limit of detection (LOD - 0.009) corresponds to the horizontal intersection of the y-intercept of the PI with the calibration line (Figure 2). A measured $\mathrm{CN}^{-} / \mathrm{C}_{2}^{-}$ratio lower than the LOD cannot be distinguished from zero [37]. The limit of quantification (LOQ - 0.018) corresponds to the horizontal intersection of the upper y-intercept of the PI with the lower bound of the CI (Figure 2). Below the LOQ, N/C values cannot be quantified [37]. With the settings used for the present contribution, a measured $\mathrm{CN}^{-} / \mathrm{C}_{2}{ }^{-}$value of 0.5 for example will correspond to a 'true' N/C value of $0.056 \pm 0.009(2 \sigma)$. The level of precision that can be reached using NanoSIMS in the present configuration is thus twice as better as the one reported in the literature [19].

We attribute such a good precision level to the low dispersion around the calibration curve of the data reported in the present contribution compared to data reported by Thomen et al. [19]. Such improvement, indicating a better repeatability of NanoSIMS measurements (Figure 2), mostly relies on sample preparation. In contrast to Thomen et al. [19] who pressed their samples at $50 \mathrm{~kg}$ or less, the reference samples measured in the present contribution have been pressed at 0.5 ton, in order to limit sample topography. This is of primary importance as the sputtering yield increases with rising angle of incidence of the primary beam (from the zero - normal incidence) due to the ejection of primary recoil atoms [38]. This is well illustrated by the $\mathrm{CN}^{-}$intensities measured on the fractured zones of the tryptophan reference sample (Figure 1A). In addition, selecting the ROIs with care, on flat and smooth areas, enhances both linearity and measurement repeatability. Following these precautions, the final relative standard deviations of N/C estimations for the reference samples used in the present contribution are $11 \%$ for the type III kerogen, $10 \%$ for the type I kerogen, $4 \%$ for the epoxide resin, $7 \%$ for the phenylalanine and $2 \%$ for the 
tryptophan. The Nebulotron reference sample could however not be measured by NanoSIMS (see section 4.1.2).

\subsubsection{Sensitive carbon materials and primary beam damage}

Steady-state emission of secondary ions requires a sufficient implantation of $\mathrm{Cs}^{+}$before analysis. Yet, the primary beam may severely damage organic surfaces [39]. Figures 1C and 1D show SEM images of the tryptophan and the Nebulotron reference samples after NanoSIMS measurements, respectively. While the surface of the tryptophan reference sample seems to have been unmodified, the Nebulotron reference sample has experienced severe structural damage preventing any reliable NanoSIMS measurements. The origin of this structural modification might be related to the aliphatic nature of the Nebulotron reference sample, which makes it very sensitive to scission chain and crosslinking processes. Indeed, thermochemical processes induced by the NanoSIMS ion beam may induce cyclization, aromatization and condensation of organic materials [40]. In particular, the ion beam may trigger the production of reactive free radicals from the cleavage of chemical bonds. These radicals may chemically react with the surrounding matrix and form conjugated double bonds or two- or three- dimensional cross-linked structures [41], which would eventually lead to network-like structures similar to those observed for the Nebulotron reference sample (Figure 1D). NanoSIMS may thus not be used with sensitive organics and carbon materials.

\subsection{STXM Measurements}

\subsubsection{Limits and Precision}

Uncertainties on XAS-based N/C estimations may arise from poor signalto-noise ratios as well as from local sample topography which may be responsible for small-angle beam scattering. Yet, these two effects appear negligible compared to the error on estimations that might result from poor fit appreciation. A way to quantify such an error is illustrated on Figure 3. Compared to the best 
fit (blue curve - Figures $3 \& 4$ ), poor fits either slightly overestimate the carbon quantity and underestimate the nitrogen quantity or vice versa. We define the stage at which these poor fits may not be considered as acceptable fits anymore using the $\alpha$ criterion such as $\alpha=\frac{\overline{\mathrm{r}}^{2} \text { poor }}{\overline{\mathrm{r}}^{2} \text { best }}=2.5$, where $\overline{\mathrm{r}^{2}}$ poor and $\overline{\mathrm{r}^{2}}$ best are, in the energy range covering the $\mathrm{C}$ and $\mathrm{N}$ post-edge regions, the mean value of the squared residuals of a poor fit and of the best fit, respectively. A value of $\sim 2.5$ corresponds to the $\alpha$ value of the $95 \%$ confidence interval of a linear regression model fitting the $\mathrm{C}$ post-edge region of the Nebulotron XAS spectrum.

We thus define here the two 'extreme fits' (i.e. the poorest fits that may remain acceptable) as the poor fits exhibiting $\alpha$ values of $\sim 2.5$. The difference in N/C ratios estimated from these 'extreme fits' (green and red dashed curves shown on Figures 3 \& 4) may be seen as a quasi-certain interval for the N/C ratio. Note that, except for the Resin reference sample that exhibits oscillations above the $C$ - and $N$ - edges that induce high incertitude on the fit $( \pm 0.02)$, this error on N/C ratio estimations from XAS data remains very low $(\leq 0.01)$, even for the type III kerogen reference sample that exhibits a N/C ratio lower than 0.02. Unfortunately, estimating the exact limit of nitrogen detection in organics and carbon materials using STXM-based XAS may not be done from the data reported in the present contribution and would require additional work on nitrogen-free organics.

4.2.2. Caution for accurately estimate N/C ratios from STXM-based XAS experiments

In addition to uncertainties on XAS-based N/C estimations that may arise from small-angle scattering caused by local sample topography, special care is needed when dealing with highly ordered carbon materials such as graphite for instance. The atomic scattering factors can be used to model the absorption signal if the X-ray scattering by individual atoms within a system is essentially unaffected by the condensed state of the system [33,34]. This is not exactly true for samples exhibiting a higher degree of atomic organization as they may exhibit EXAFS structures (i.e., oscillations above the $K$-edges) over an energy range of about $500 \mathrm{eV}$ [42]. In addition, nitrogen overestimation may occur when the 
investigated organics are closely associated with clay minerals that may host nitrogen as ammonia within interlayer spaces [43,44]. Acquiring X-ray absorption spectra over the entire $\mathrm{C}+\mathrm{N}$ energy range thus appears important in order to identify these clays minerals based on their potassium (K $L$-edge region - 295-305 eV) and calcium (Ca $L$-edge region - 340-360 eV) contents.

5. Concluding remarks: Benefits and Limitations of NanoSIMS and STXM-based XAS for N/C estimations

Following recent attempts reported in the literature, the present paper discusses two methods of quantification of the N/C ratio or organics and carbon materials using NanoSIMS and STXM-based XAS. As illustrated here, these two techniques allow accurately estimating N/C ratios at the submicrometer scale with a high level of precision. Carefully preparing the samples for NanoSIMS experiments has led to a confidence level for N/C estimations of \pm 0.009 (95\%), which is twice as better as previously reported in the literature by Hatton et al. [1] or Thomen et al. [19]. Similar precision can be reached using STXM-based XAS as shown by the experiments reported in the present contribution which hence validates the methodology recently adopted by Cody et al. [20,21].

Although these two techniques offer the same level of precision and very low limits of detection and quantification, they do not present the same limitations. STXM experiments require samples to be transparent to X-rays and hence necessitate to either prepare ultrathin sections of samples or finely crush the investigated samples to obtain very fine-scale powdered samples. In contrast, NanoSIMS experiments may only be done on perfectly flat surfaces and thus require either pressing or finely polishing the investigated samples. Depending on the nature of the investigated materials, such complex sample preparation procedures may constitute a severe limitation. In addition, NanoSIMS experiments may not be performed on sensitive samples as they may encompass critical structural modifications due to primary beam damage.

Both techniques allow estimating N/C ratios over a wide range of values. As shown here, STXM-based XAS allows directly estimating N/C ratios of organics without using any standard. In contrast, NanoSIMS-based N/C 
estimations require at least two standards to be measured using the same analytical settings in order to build the calibration line necessary to properly inverse $\mathrm{CN}^{-} / \mathrm{C}_{2}^{-}$ratios. Even though it may not be mandatory, the most rigorous way to precisely estimate the N/C ratio of an unknown sample would be to use two standards exhibiting N/C ratios that will bracket the unknown value. Obviously, this might be difficult to achieve for truly unknown samples.

The benefits and limitations of NanoSIMS and STXM-based XAS also differ for organics closely associated with inorganic phases or embedded within inorganic matrices. As stated above, special care is needed when using STXMbased XAS to estimate N/C ratios of organics closely associated with N-rich inorganic phases. In contrast, such N-rich inorganic phases will not significantly contribute to the cyanide ion $\left(\mathrm{CN}^{-}\right)$count rate and will thus not impact, as such, the estimations of N/C ratios by NanoSIMS. Still, the presence of inorganic phases may influence the ionization rate of organics and carbon materials through the so-called matrix effect.

Finally, despite these different limitations, it should be kept in mind that NanoSIMS and STXM-based XAS constitute highly complementary characterization techniques. As a matter of fact, concomitantly with estimations of N/C ratios of organics and carbon materials, NanoSIMS may provide estimations of their isotopic signatures $\left(\delta^{13} \mathrm{C}\right.$ and $\delta^{15} \mathrm{~N}$, for instance) while STXM-based XAS may provide information on their molecular signatures (carbon and nitrogen speciation, for instance), both at the submicrometer scale. Combining these two techniques thus appears particularly valuable for the finescale characterization of organics and carbon materials. 


\section{Acknowledgements}

We gratefully acknowledge support from the ERC (project PaleoNanoLife - PI: F. Robert) as well as Maïa Kuga for providing the Nebulotron reference sample. The SEM facility of the IMPMC was supported by Region Ile de France grant SESAME 2006 I-07-593/R, INSU-CNRS, INP-CNRS, University Pierre et Marie Curie Paris 6. The National NanoSIMS Facility at the MNHN was supported by MNHN, CNRS, Region Ile de France, Ministère de l'Enseignement supérieur et de la Recherche. STXM-based XAS data were acquired at beamline 10ID-1 at the CLS, which is supported by the NSERC, the CIHR, the NRC, and the University of Saskatchewan. Special thanks go to Chithra Karunakaran and Jian Wang for their expert support of the STXM at the CLS. 


\section{Reference}

[1] Hatton P-J, Remusat L, Zeller B, Derrien D. A multi-scale approach to determine accurate elemental and isotopic ratios by nano-scale secondary ion mass spectrometry imaging. Rapid Commun Mass Spectrom 2012; 26: 1363-71.

[2] Remusat L, Hatton P-J, Nico PS, Zeller B, Kleber M, Derrien D. NanoSIMS study of organic matter associated with soil aggregates: advantages, limitations, and combination with STXM. Environ Sci Technol 2012; 46: 3943-9.

[3] De Gregorio BT, Sharp TG, Flynn GJ, Wirick S, Hervig RL. Biogenic origin for Earth's oldest putative microfossils. Geology 2009; 37: 631-4.

[4] Wacey D, Kilburn MR, Saunders M, Cliff J, Brasier MD. Microfossils of sulphur-metabolizing cells in 3.4-billion-year-old rocks of Western Australia. Nature Geosci 2011; 4: 698-702.

[5] Wang X, Li X, Zhang L, Yoon Y, Weber PK, Wang H, et al. N-Doping of graphene through electrothermal reactions with ammonia. Science 2009; 324: $768-71$.

[6] Ayala P, Arenal R, Rümmeli M, Rubio A, Pichler T. The doping of carbon nanotubes with nitrogen and their potential applications. Carbon 2010; 48: 57586.

[7] Yamada Y, Kim J, Matsuo S, Sato S. Nitrogen-containing graphene analyzed by X-ray photoelectron spectroscopy. Carbon 2014; 70: 59-74.

[8] Lal R. Soil carbon sequestration impacts on global climate change and food security. Science 2004; 304: 1623-7.

[9] Schulze ED, Freibauer A. Carbon unlocked from soils. Nature 2005; 437: 205-206.

[10] Young IM, Crawford JW. Interactions and self-organization in the soilmicrobe complex. Science 2004; 304: 1634-7.

[11] Lehmann J, Solomon D, Kinyanghi J, Dathe L, Wrick S, Jacobsen C. Spatial complexity of soil organic matter forms at nanometre scales. Nature Geosci 2008; $1: 238-42$.

[12] Lehmann MF, Bernasconi SM, Barbieri A, McKenzie JA. Preservation of organic matter and alteration of its carbon and nitrogen isotope composition 
during simulated and in situ early sedimentary diagenesis. Geochim Cosmochim Acta 2002; 66: 3573-84.

[13] Oehler DZ, Robert F, Walter MR, Sugitani K, Allwood A, Meibom A, et al. NanoSIMS: insights to biogenicity and syngeneity of Archaean carbonaceous structures. Precamb Res 2009; 173: 70-8.

[14] Van Zuilen MA, Chaussidon M, Rollion-Bard C, Marty B. Carbonaceous cherts of the Barberton Greenstone Belt, South Africa: isotopic, chemical and structural characteristics of individual microstructures. Geochim Cosmochim Acta 2007; 71: 655-69.

[15] Wacey D, McLoughlin N, Kilburn MR, Saunders M, Cliff JB, Kong C, et al. Nanoscale analysis of pyritized microfossils reveals differential heterotrophic consumption in the $\sim 1.9$ Ga Gunflint chert. Proceedings of the National Academy of Sciences 2013; 100(20):8020-4.

[16] Schimmelmann A, Lis GP. Nitrogen isotopic exchange during maturation of organic matter. Org Geochem 2010; 41: 63-70.

[17] Robertson J, Davis CA. Nitrogen doping of tetrahedral amorphous carbon. Diamond and Related Materials 1995; 4:441-4.

[18] Ewels CP, Glerup M. Nitrogen doping in carbon nanotubes. J Nanosci Nanotechnol 2005; 5: 1345-63.

[19] Thomen A, Robert F, Remusat L. Determination of the nitrogen abundance in organic materials by NanoSIMS quantitative imaging. $J$ Anal At Spectrom 2014; 29: 512-9.

[20] Cody GD, Ade H, Alexander CMO'D, Araki T, Butterworth A, Fleckenstein $\mathrm{H}$, et al. Quantitative organic and light-element analysis of comet $81 \mathrm{P} / \mathrm{Wild} 2$ particles using C-, N-, and O- $\mu$-XANES. Meteorit Planet Sci 2008; 43: 353-65.

[21] Cody GD, Gupta NS, Briggs DEG, Kilcoyne ALD, Summons RE, Kenig F, et al. Molecular signature of chitin-protein complex in Paleozoic arthropods. Geology 2011; 39: 255-8.

[22] Van Dommele S, Romero-Izquirdo A, Brydson R, de Jong KP, Bitter JH. Tuning nitrogen functionalities in catalytically grown nitrogen-containing carbon nanotubes. Carbon 2008; 46: 138-48. 
[23] Kuga M, Carrasco N, Marty B, Marrocchi Y, Bernard S, Rigaudier T, et al. Nitrogen isotopic fractionation during abiotic synthesis of organic solid particles. Earth Planet Sci Lett 2014; 393: 2-13.

[24] Hoppe P. NanoSIMS: A new tool in cosmochemistry. Appl Surf Sci 2006; 252: 7102-6.

[25] Berkowitz J, Chupka WA, Walter TA. Photoionization of HCN: the electron affinity and heat of formation of CN. J Chem Phys 1969; 50: 1497-500.

[26] Bradforth SE, Kim EH, Arnold DW, Neumark DM. Photoelectron spectroscopy of $\mathrm{CN}^{-}, \mathrm{NCO}^{-}$, and $\mathrm{NCS}^{-}$. J Chem Phys 1993; 98: 800-10.

[27] Clode PL, Stern RA, Marshall AT. Subcellular imaging of isotopically labeled carbon compounds in a biological sample by ion microprobe (NanoSIMS). Microsc Res Tech 2007; 70: 220-9.

[28] Kaznatcheev KV, Karunakaran Ch, Lanke UD, Urquhart SG, Obst M, Hitchcock AP. Soft X-ray spectromicroscopy beamline at the CLS: commissioning results. Nucl Instrum Methods Phys Res Sect A 2007; 582: 96-9.

[29] Wang J, Morin C, Li L, Hitchcock A, Scholl A, Doran A. Radiation damage in soft X-ray microscopy. J Electron Spectrosc Relat Phenom 2009; 170(1-3): $25-36$.

[30] Hitchcock AP, Dynes JJ, Johansson G, Wang J, Botton G. Comparison of NEXAFS microscopy and TEM-EELS for studies of softmatter. Micron 2008; 39(3): 311-9.

[31] McMahon G, François Saint-Cyr H, Lechene C, Unkefer CJ. CN ${ }^{-}$Secondary ions form by recombination as demonstrated using multi-isotope mass spectrometry of ${ }^{13} \mathrm{C}$ - and ${ }^{15} \mathrm{~N}$-labeled polyglycine. J Am Soc Mass Spectrom 2006; 17: 1181-7.

[32] Stöhr J, NEXAFS spectroscopy. Springer 1992; 25.

[33] Henke BL, Lee P, Tanaka TJ, Shimabukuro RL, Fujikawa BK. Low-energy $\mathrm{X}$-ray interaction coefficients: photoabsorption, scattering, and reflection: $\mathrm{E}=$ 100-2000 eV Z = 1-94. At Data Nucl Data Tables 1982; 27: 1-144.

[34] Henke BL, Gullikson EM, Davis JC. X-ray interactions: Photoabsorption, scattering, transmission and reflection at $\mathrm{E}=50-30,000 \mathrm{eV}, \mathrm{Z}=1-92$. At Data Nucl Data Tables 1993; 54: 181-342. 
[35] Bernard S, Beyssac O, Benzerara K, Findling N, Brown Jr GE. XANES, Raman and XRD signatures of anthracene-based cokes and saccharose-based chars submitted to high temperature pyrolysis. Carbon 2010; 48: 2506-16.

[36] Le Guillou C, Remusat L, Bernard S, Brearley AJ, Leroux H. Amorphization and $\mathrm{D} / \mathrm{H}$ fractionation of kerogens during experimental electron irradiation: comparison with chondritic organic matter. Icarus 2013; 226(1): 101-10.

[37] Mermet J-M. Limit of quantitation in atomic spectrometry: an unambiguous concept? Spectrochim Acta Part B 2008; 63: 166-82.

[38] Bay HL, Bohdansky J, Hofer WO, Roth J. Angular distribution and differential sputtering yields for low-energy light-ion irradiation of polycrystalline nickel and tungsten. App Phys 1980; 21:327-33.

[39] Clough RL. High-energy radiation and polymers: A review of commercial processes and emerging applications. Nucl Instrum Meth B 2001; 185: 8-33.

[40] Sviridov DV. Chemical aspects of implantation of high-energy ions into polymeric materials. Russ Chem Rev 2002; 71:315-27.

[41] Prošková K, Švorčik V, Rybka V, Hnatowicz V. Selected degradation reactions in polyethylene irradiated with $\mathrm{Ar}+$ and $\mathrm{Xe}+$ ions. Radiat Physi Chem 2000; 58: 153-6.

[42] Comelli G, Stöhr J. SEXAFS studies of C=C bond lengths in condensed and chemisorbed molecules. Surf Sci 1988; 200: 35-44.

[43] Daniels EJ, Aronson JL, Altaner SP, Clauer N. Late Permian age of $\mathrm{NH}_{4}$ bearing illite in anthracite from eastern Pennsylvania: temporal limits on coalification in the central Appalachians. Geol Soc Am Bull 1994; 106: 760-6.

[44] Krooss BM, Jurisch A, Plessen B. Investigation of the fate of nitrogen in Palaeozoic shales of the Central European Basin. J Geochem Explor 2006; 89: $191-4$. 


\section{Table Caption}

Table 1: Bulk N/C measurements (thermal conductivity - SGS Multilab), $\mathrm{CN}^{-} / \mathrm{C}_{2}^{-}$ ionic ratios measured by NanoSIMS and N/C ratios estimated by STXM-based XAS.

\section{Figure Caption}

Figure 1: A. NanoSIMS image of Tryptophan the color scale shows the secondary $C N^{-}$intensities per pixel). The black square corresponds to one of the 30 selected ROIs for Tryptophan. B. NanoSIMS image of Nebulotron the color scale shows the secondary $C N^{-}$intensities per pixel). C. SEM image of the Tryptophan sample after NanoSIMS experiments. D. SEM image of the Nebulotron sample after NanoSIMS experiments. Darker zones on SEM images correspond to cesium implanted zones. Red squares on SEM images $C$. and D. indicate the measured $10 \times 10 \mu^{2}$ areas shown in A. and B., respectively. Scale bar is $2 \mu \mathrm{m}$.

Figure 2: Plot showing the $\mathrm{CN}^{-} / \mathrm{C}_{2}^{-}$values extracted from NanoSIMS experiments for all the investigated reference samples but the Nebulotron sample as a function of their bulk atomic N/C ratios. Each diamond represents a ROI of 0.5 $\mu \mathrm{m}^{2}$. "LOD" is the limit of detection, "LOQ" is the limit of quantification and "PI" and "CI" are the prediction and confidence intervals, respectively (see discussion for details).

Figure 3: X-ray absorption spectrum of the Nebulotron reference sample (black) in the energy range covering the $C$ and $N K$-edges. Also shown in blue is the best fit $\left(K_{C} \times f_{2(\text { carbon })}+K_{N} \times f_{2(\text { nitrogen })}\right)$, the $K_{N} / K_{C}$ ratio corresponding to the $N / C$ atomic ratio. A-B. Details of the carbon and nitrogen post-edge regions showing 'extreme fits' (in red and green) which are defined as the poor fits exhibiting $\alpha$ values of $\approx 2.5$ (see text for details). The green dashed curve overestimates the carbon quantity and underestimates the nitrogen quantity while the red dashed curve underestimates the carbon quantity and overestimates the nitrogen quantity. The difference in N/C estimations between the two 'extreme fits' (the green and red dashed curves) is defined as the error on the estimation.

Figure 4:A-F. X-ray absorption spectra of the six investigated reference samples (black), best fits (blue) and 'extreme fits' (red and green). G. Plot showing the $N / C$ values estimated from $S T X M$-based XAS experiments (i.e., $K_{N} / K_{C}$ ratios) for all the investigated reference samples as a function of their bulk atomic N/C ratios. Note that the regression curve between the ratios $K_{N} / K_{C}$ and the $N / C$ bulk measurements is very close to a straight line with a slope of 1 passing through the origin. For each reference sample, the error bar corresponds to the difference between estimations from the 'extreme fits'. 


\section{ACCEPTED MANUSCRIPT}

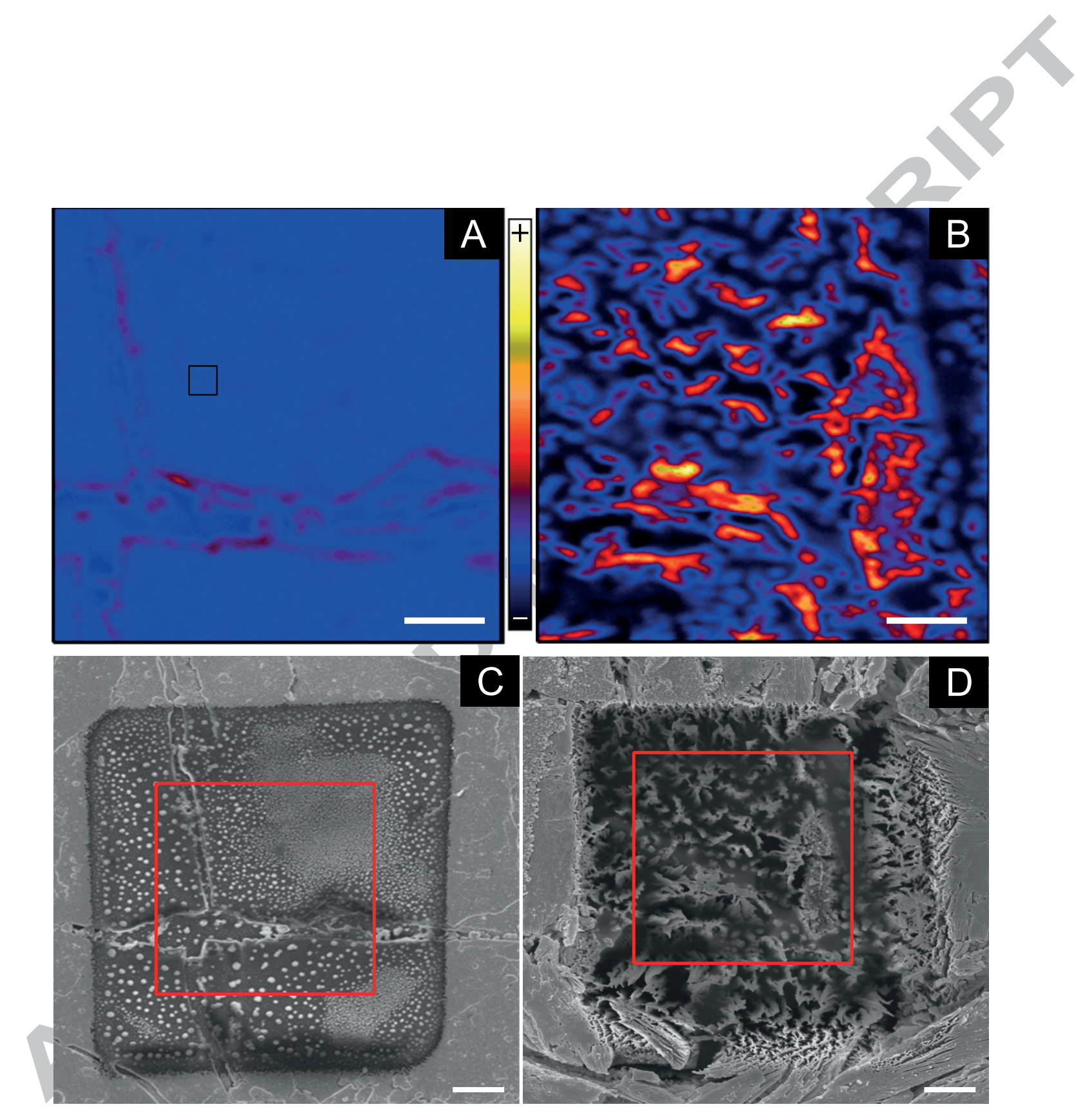

Figure 1 


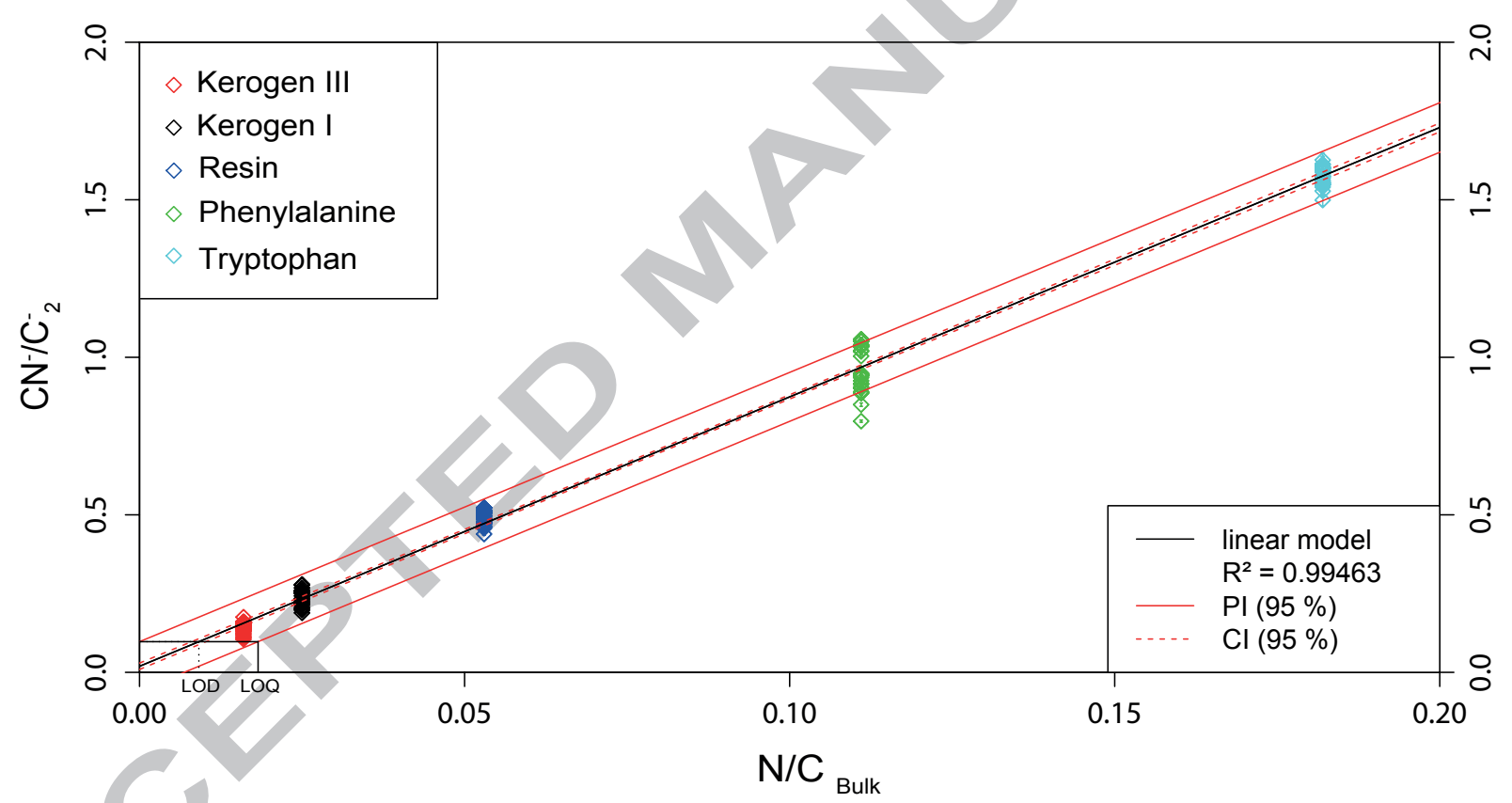

Figure 2 
